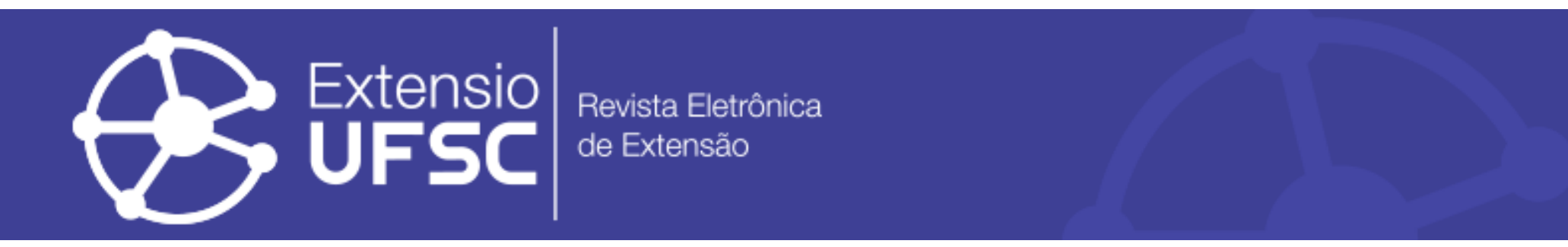

\title{
PROCESSO DE FORMAÇÃO E INCLUSÃO TECNOLÓGICA PARA A TERCEIRA IDADE
}

\author{
Taiane Souza Paixão \\ Universidade Federal do Paraná \\ taiane.canuto@gmail.com \\ Maria do Carmo Duarte Freitas \\ Universidade Federal do Paraná \\ carmemk2@gmail.com
}

\begin{abstract}
Resumo
Analisar o processo de aprendizagem de e-inclusão da Terceira Idade na Universidade Federal do Paraná, atividade desenvolvida por membros do Grupo de Pesquisa em Ciência Informação e Tecnologia (GP-CIT) uma parceria entre dois programas extensionistas. Em seu sétimo ano, a Universidade Aberta da Maturidade (UAM) forma em média 70 pessoas a cada ano. A pesquisa utiliza dados de quatro anos de projeto, em cursos de dois meses de duração. O procedimento metodológico adotado é pesquisa-ação, de natureza aplicada e a análise dos dados quali-quantitativo, o qual conduziu a constatação que os idosos entravam com poucas noções de informática e ao final com um conhecimento mais amplo dos conteúdos. O projeto estimula o desenvolvimento de competências tecnológicas entre os participantes com ações educativas sobre as mídias e recursos disponíveis na internet. Promovendo meios para que se apropriem das tecnologias para usufruto pessoal e social.
\end{abstract}

Palavras-chave: Aprendizagem. E-Inclusão. Terceira Idade.

\section{THE PROCESS OF FORMATION AND INCLUSION OF TECHNOLOGY FOR THE THIRD AGE}

\begin{abstract}
To analyse the e-inclusion learning process of the Third Age at the Federal University of Paraná, an activity developed by members of the Group of Research in Science Information and Technology (GP-CIT) a partnership between two extensions programs. In its seventh year, the Open University of Maturity (UAM) makes an average of 70 people each year. The survey uses data from four years of project in two-month courses. The methodological procedure adopted is action research, of an applied nature and the qualitative-quantitative data analysis leads to the finding that the elderly entered with few notions of computer science and in the end with a broader knowledge of the contents. The project stimulates the development of technological skills among participants with educational actions on the media and resources available on the internet. Promoting means to take ownership of technologies for personal and social enjoyment.
\end{abstract}

Keywords: E-inclusion. Learning. Third Age.

\section{E1 PROCESO DE FORMACIÓN Y INCLUSIÓN DE LA TECNOLOGÍA EN LA TERCERA EDAD}

\section{Resumen}

El análisis de los procesos de aprendizaje de e-inclusión de la Tercera Edad en la Universidad Federal de Paraná, actividad desarrollada por miembros del Grupo de Investigación en Ciencia Información y Tecnología (GP-CIT) una asociación entre dos programas extensionistas. En su séptimo año, la Universidad Abierta de la Madurez (UAM) forma en promedio a 70 personas cada año. La investigación utiliza datos de cuatro años de proyecto, en cursos de dos meses de duración. El procedimiento metodológico adoptado es investigación-acción, de naturaleza aplicada y el análisis de los datos cualicuantitativo conduce a la constatación que los ancianos entraban con pocas nociones de informática y al final con un conocimiento más amplio de los contenidos. El proyecto estimula el desarrollo de competencias tecnológicas entre los participantes con acciones educativas sobre los medios y recursos disponibles en Internet. Promoviendo medios para que se apropien de las tecnologías para usufructo personal y social.

Palabras clave: Aprendizaje. E-inclusión. Tercera Edad. 


\title{
INTRODUÇÃO
}

Com o desenvolvimento tecnológico o uso do computador e internet tem importância considerável no dia a dia do indivíduo, entretanto alguns não possuem acesso devido a limitações físicas e intelectuais. Um dos públicos que são lesionados com esses problemas são os idosos, pois estes possuem limitações como: alterações cognitivas, visuais, auditivas e de movimentação (SILVA et al., 2011). Além dessas limitações, os idosos também enfrentam um preconceito diante a sociedade, sendo vistos como pessoas inválidas e improdutivas (SALES, 2002).

O Instituto Brasileiro de Geografia e Estatística (2016) mostra que existe um aumento de pessoas com idade superior a 60 anos no Brasil, aproximadamente 14,5 milhões de pessoas têm idade superior a 60 anos, a World Health Organization (2015) estima que em 2050 20\% da população brasileira terá mais de 60 anos no Brasil.

De acordo com o Estatuto do Idoso:

\begin{abstract}
Art. 20. O idoso tem direito a educação, cultura, esporte, lazer, diversões, espetáculos, produtos e serviços que respeitem sua peculiar condição de idade.

Art. 21. O Poder Público criará oportunidades de acesso do idoso à educação, adequando currículos, metodologias e material didático aos programas educacionais a ele destinados.

$\int 10$ Os cursos especiais para idosos incluirão conteúdo relativo às técnicas de comunicação, computação e demais avanços tecnológicos, para sua integração à vida moderna. (BRASIL, 2003)
\end{abstract}

Neste cenário tem-se o seguinte problema de pesquisa: Qual a importância do projeto de Inclusão Digital para os idosos?

Os objetivos da pesquisa para o entendimento da intenção e dos propósitos são divididos em geral e específicos. Como objetivo geral a expectativa é analisar o processo de aprendizagem de e-inclusão da terceira idade na Universidade Federal do Paraná.

Para se atingir o objetivo geral, foram desenvolvidos objetivos específicos para a presente pesquisa:

a) definir o perfil do idoso participante do projeto de inclusão digital;

b) analisar o conhecimento adquirido ao longo do curso de inclusão digital;

c) criação de um mapa com os grupos de pesquisas do Brasil inteiro relacionados ao tema idoso.

A pesquisa foi realizada no Grupo de Pesquisa em Ciência Informação e Tecnologia (GPCIT), no projeto de mídia digital, há mais de cinco anos, porém nenhuma pesquisa havia sido desenvolvida a partir dos dados coletados no projeto, para analisar o perfil dos idosos e mostrar a importância de seu desenvolvimento. Além disso, o projeto permite a inserção de graduandos e 
professores, fato que dá maior familiaridade com o tema sobre o viés social do desenvolvimento do mesmo.

Para embasamento teórico, este artigo traz uma busca no Diretório dos Grupos de Pesquisa no Brasil Capes sobre o tema idoso. Para recuperar a informação, foram utilizadas as palavras "idoso" e "terceira idade". Na primeira busca foram encontrados 588 grupos de pesquisa e na segunda 57. Verificou-se a existência de dados duplicados e após as análises ficaram 622 dados. Por meio desses dados criou-se um mapa (Figura 1) contendo a quantidade de grupos de pesquisa por Universidades/Institutos/Faculdades de cada estado do Brasil.

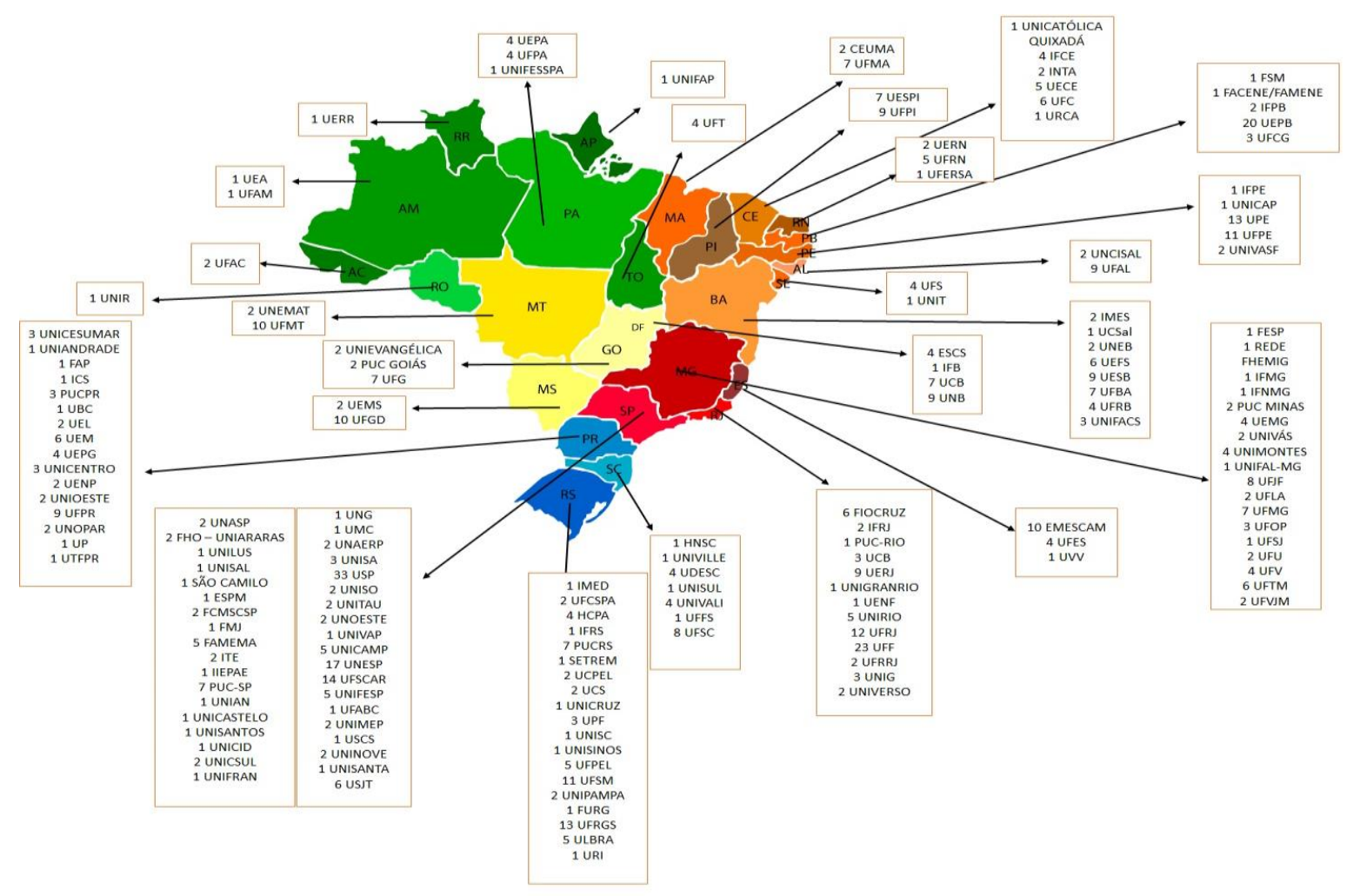

Figura 1 - Mapa dos grupos de pesquisa com o tema idoso no brasil Fonte: Elaborado pela autora.

Nesse mapa se observa a predominância de estudos no estado de São Paulo e Rio Grande do Sul, que apresentam respectivamente 134 e 64 grupos de pesquisa. Também se verificou que a Universidade de São Paulo (USP) é a instituição que mais apresentou grupos de pesquisa, ao todo 33 grupos. Outra evidência que a Figura 1 aponta é a escassez de publicações no Estado de Roraima, Rondônia e Amapá onde aparecem apenas um grupo por estado.

Foi feita uma segunda pesquisa com o tema "Inclusão Digital Idoso" e "Inclusão digital Terceira Idade", a primeira pesquisa resultou em quatro grupos e a segunda não foi encontrado nenhum grupo. 
Processo de formação e inclusão tecnológica para a terceira idade

Para tanto, por meio dos dados desses quatro grupos, foi criado um segundo mapa (Figura 2) onde apareceram apenas um grupo de pesquisa nos estados do Rio Grande do Norte, Paraná, São Paulo e Santa Catarina. O mapa apresenta o nome das Universidades que estão estudando sobre inclusão digital do idoso de acordo com os estados do Brasil.

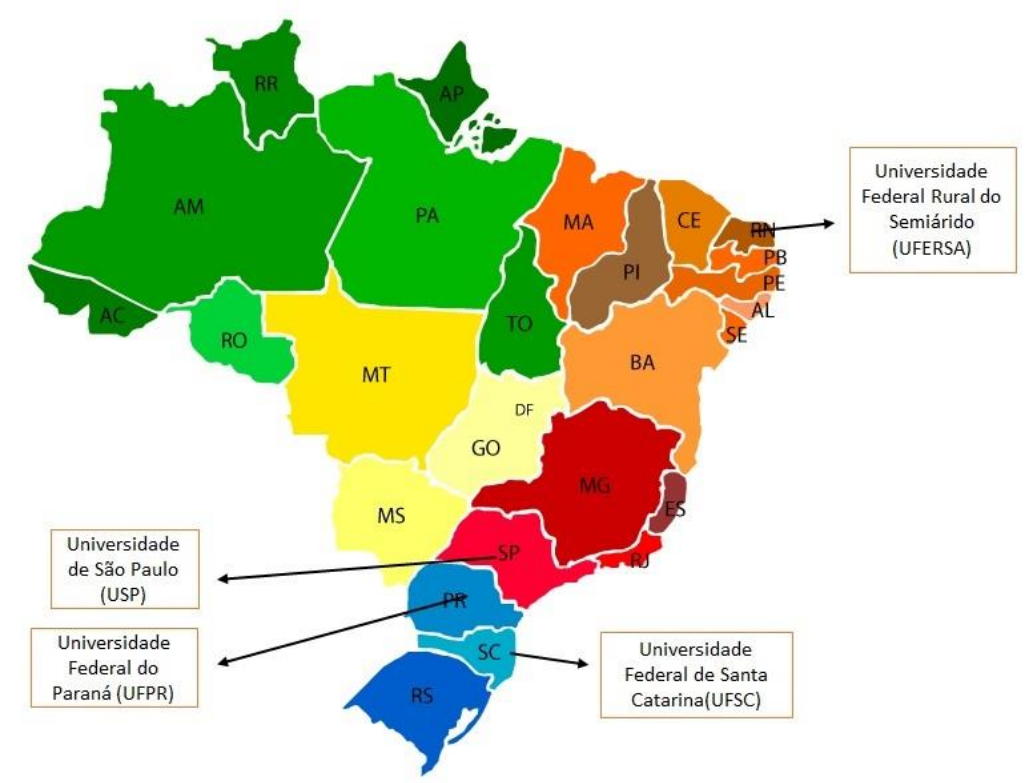

Figura 2 - Mapa dos grupos de pesquisa que estudam/estudaram sobre inclusão digital do idoso Fonte: Elaborado pela autora.

\section{MATERIAIS E MÉTODOS}

A Universidade Aberta da Maturidade (UAM) é um Projeto Extensionista da Reitoria da UFPR. O curso tem em média um ano e é destinado a pessoas com mais de 60 anos. Tem como meta valorizar socialmente o idoso e contribuir para a promoção da qualidade de vida e do desenvolvimento cultural e social dos participantes. O projeto tem como base os seguintes temas centrais: Inclusão Digital, Direito do Idoso, Saúde do Idoso, Atividades Corporais, Meio Ambiente, Gerontologia, Arte e Cultura. (UAM, 2016).

As atividades relacionadas à Inclusão Digital acontecem no Campus Jardim Botânico, prédio de Ciências Sociais Aplicadas. Essas atividades são exercidas pelo Grupo GP-CIT, pois é uma atividade extensionista, onde as aulas ofertadas são: Conhecendo o Computador, Aprendendo a Desenhar com o Mouse, Cloud Computing, Montando Apresentações, Montando Tabelas, Editando Texto, Segurança, Redes Sociais e Oficina do Mapa Verde (Quadro 1) 
Durante as aulas também são utilizados livretos de cada curso ofertado, estes servem de auxílio para os idosos, o material foi desenvolvido pelo grupo de pesquisa ao longo dos anos para aprimorar o ensino nas aulas de inclusão digital.

\begin{tabular}{|l|l|}
\hline Temas & Conteúdo das Aulas \\
\hline Apresentação de Instruções Digitais & Noções básicas do computador e meios digitais \\
\hline Conhecendo Computador & $\begin{array}{l}\text { Como ligar o computador, como usar a área de trabalho, salvar um } \\
\text { arquivo, excluir um arquivo, deligar o computador, uso do } \\
\text { navegador }\end{array}$ \\
\hline Aprendendo a desenhar o Mouse & $\begin{array}{l}\text { Paint e suas versões, primeiro desenho, mover objetos, importar } \\
\text { imagens, colorir e salvar o desenho }\end{array}$ \\
\hline Editando Texto (Word) & $\begin{array}{l}\text { Criar um documento, fontes e tamanhos, inserir uma imagem, } \\
\text { copiar e colar textos, cabeçalho e rodapé, inserir elementos gráficos } \\
\text { e salvar documento }\end{array}$ \\
\hline Montando Tabelas (Exce) & Criar um documento, inserir dados e fórmulas e salvar o documento \\
\hline Montando Apresentações & $\begin{array}{l}\text { Escrever nos Slides, inserir imagens e clip-arts, inserir sons e salvar } \\
\text { apresentação }\end{array}$ \\
\hline Redes Sociais (Facebook) & $\begin{array}{l}\text { Como inserir imagens, como compartilhar imagens, como fazer } \\
\text { uma postagem, como criar uma página }\end{array}$ \\
\hline Segurança & Segurança na Internet \\
\hline Cloud Computing & $\begin{array}{l}\text { O que é, criar documentos, fazer upload, fazer download, organizar } \\
\text { arquivos, compartilhar arquivos e enviá-los por e-mail. }\end{array}$ \\
\hline Oficina Mapa Verde & $\begin{array}{l}\text { São mapeados os lugares onde os idosos conhecem perto de suas } \\
\text { casas, com o lema: Pense local, mapeie Global! O objetivo é } \\
\text { desenvolvimento da qualidade de vida cultural e social dos } \\
\text { participantes. }\end{array}$ \\
\hline
\end{tabular}

Quadro 1 - Temas e conteúdo do curso de Inclusão digital para participantes da UAM Fonte: Elaborado pela autora

A pesquisa foi aplicada com os idosos do projeto de Inclusão Digital por meio de um questionário nos anos de 2014, 2015, 2016, 2017. O questionário é composto por 13 questões, sendo 12 fechadas e uma aberta, todas as questões fechadas possuem as alternativas: a) Não tenho a menor ideia; b) Tenho uma vaga noção; c) Sei, mas preciso estudar mais; d) Tenho bastante conhecimento.

Para facilitar o entendimento e posteriormente apresentação dos resultados o questionário foi dividido em quatro blocos:

I. Funcionalidades do Computador: questões relacionadas a base para funcionar um computador, sistema operacional, o próprio computador, periféricos, hardwares e softwares.

II. Aplicações do Computador: softwares que funcionam off-line que são: Excel, Powver Point e Word.

III. Acesso Online: programas que precisam da internet para funcionar, Internet, Navegador, Facebook e cloud computing

IV. Segurança da Informação: fatores de segurança tanto online como off-line. 
Processo de formação e inclusão tecnológica para a terceira idade

A intenção do questionário além de extrair os dados para análise, foi dividir as turmas da UAM em duas segundo o nível de conhecimento do grupo. Essa divisão foi necessária para utilizar a metodologia mais adequada em sala de aula.

Além do questionário mencionado acima, na turma de 2017 também foi aplicado um questionário de satisfação ao término de cada curso, o questionário tinha cinco questões fechadas: Conteúdo do Curso, Tempo de duração da aula, Pontualidade dos Monitores, Aprendizagem do Idoso e Local do Curso. Na avaliação, o idoso deveria colocar uma nota de 1 a 4 em cada tópico, sendo 1 ruim, 2 regular, 3 Bom e 4 muito bom, a última questão foi aberta para comentários.

\section{RESULTADOS E ANÁLISES}

A partir de 2014, em todos os anos adotou-se um único instrumento que tinha a intenção de identificar quais os conhecimentos mínimos dos participantes para iniciar a sua formação e inclusão tecnológica.

A Figura 3 apresenta o total de participantes ao longo do ano. Sendo que o ano de 2015 foi o que mais teve participantes. No ano de 2017 foi aplicado o questionário com os alunos da UAM. Ao todo foram respondidos 80 questionários.

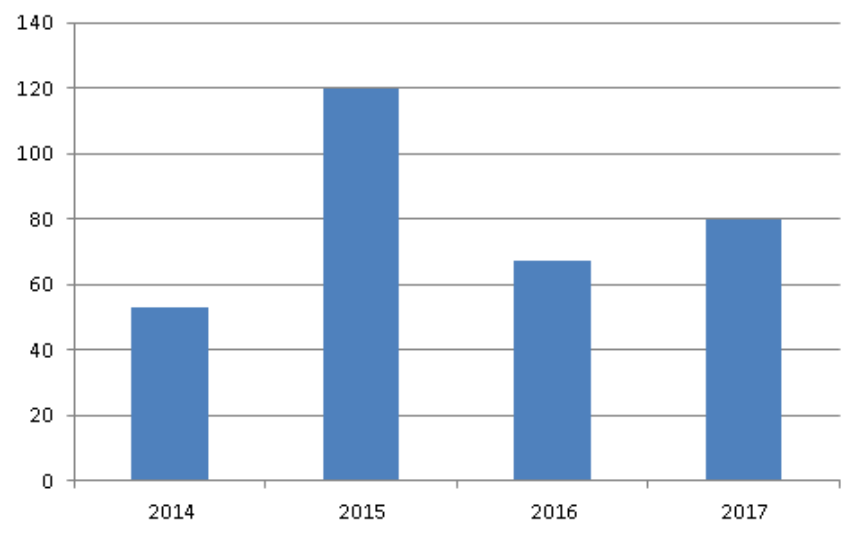

Figura 3 - Total de participantes da UAM por ano Fonte: Elaborado pela autora.

A seguir serão apresentados os dados e as análises obtidas dos questionários aplicados a UAM, para facilitar a análise, as competências "Não tenho a menor ideia" e "Tenho uma vaga noção" foram somadas e mostradas como uma competência de "Não saber usar o computador" e as alternativas "Sei, mas preciso estudar mais" e "Tenho bastante conhecimento", também foram somadas e indicadas como "Sabem usar o computador". 
A Tabela 1 mostra o conhecimento dos idosos em relação as noções básicas do computador.

\begin{tabular}{|c|c|c|c|c|}
\hline \multirow[b]{2}{*}{ Ano } & \multirow[b]{2}{*}{ Alternativas } & \multicolumn{3}{|c|}{ Tabela de Frequência Relativa } \\
\hline & & $\begin{array}{c}1 \text { - Uso do } \\
\text { Computador }\end{array}$ & $\begin{array}{c}2 \text { - Sistema } \\
\text { Operacional }\end{array}$ & $\begin{array}{c}4- \\
\text { Periféricos }\end{array}$ \\
\hline \multirow{4}{*}{ 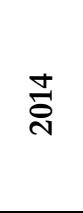 } & Não tenho a menor ideia & $8 \%$ & $26 \%$ & $34 \%$ \\
\hline & Tenho uma vaga noção & $25 \%$ & $32 \%$ & $32 \%$ \\
\hline & Sei, mas preciso estudar mais & $64 \%$ & $40 \%$ & $34 \%$ \\
\hline & Tenho bastante conhecimento & $4 \%$ & $2 \%$ & $0 \%$ \\
\hline \multirow{5}{*}{ 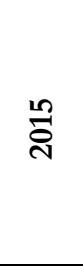 } & Não tenho a menor ideia & $13 \%$ & $24 \%$ & $31 \%$ \\
\hline & Tenho uma vaga noção & $18 \%$ & $20 \%$ & $18 \%$ \\
\hline & Sei, mas preciso estudar mais & $60 \%$ & $50 \%$ & $45 \%$ \\
\hline & Tenho bastante conhecimento & $9 \%$ & $4 \%$ & $4 \%$ \\
\hline & Nulo & $1 \%$ & $2 \%$ & $2 \%$ \\
\hline \multirow{5}{*}{ 웅 } & Não tenho a menor ideia & $9 \%$ & $51 \%$ & $45 \%$ \\
\hline & Tenho uma vaga noção & $34 \%$ & $22 \%$ & $36 \%$ \\
\hline & Sei, mas preciso estudar mais & $51 \%$ & $19 \%$ & $18 \%$ \\
\hline & Tenho bastante conhecimento & $3 \%$ & $4 \%$ & $0 \%$ \\
\hline & Nulo & $3 \%$ & $3 \%$ & $1 \%$ \\
\hline \multirow{5}{*}{ 궁 } & Não tenho a menor ideia & $16 \%$ & $41 \%$ & $48 \%$ \\
\hline & Tenho uma vaga noção & $33 \%$ & $24 \%$ & $21 \%$ \\
\hline & Sei, mas preciso estudar mais & $48 \%$ & $30 \%$ & $26 \%$ \\
\hline & Tenho bastante conhecimento & $4 \%$ & $1 \%$ & $1 \%$ \\
\hline & Nulo & $0 \%$ & $4 \%$ & $4 \%$ \\
\hline
\end{tabular}

A análise da Tabela 1 demonstra que em 2014 cerca de 70\% dos idosos disseram que sabiam usar o computador, em contraponto $58 \%$ não sabiam o que era um sistema operacional. No ano de 2015 69\% disseram ter bastante domínio do computador e 44\% não sabiam o que era um sistema operacional. Em 2016 54\% dos idosos disseram que tinham bastante domínio do computador e 81\% informou não saber o que é um periférico. Em 2017 52\% disseram saber usar o computador e $69 \%$ disseram não saber o que é um periférico.

A Tabela 2 avaliou o conhecimento dos idosos em relação ao uso de programas como editor de texto, desenho, apresentações e planilhas eletrônicas. 


\begin{tabular}{|c|c|c|c|c|}
\hline & \multirow{2}{*}{\multicolumn{3}{|c|}{ Tabela de Frequência Relativa }} \\
\hline & & & & \\
\hline Ano & Alternativas & $\begin{array}{l}3 \text { - Editores de Desenhos } \\
\text { e textos }\end{array}$ & $\begin{array}{l}\text { 5- Montagem de } \\
\text { Apresentações } \\
\end{array}$ & 6 - Planilha Eletrônica \\
\hline \multirow{4}{*}{$\stackrel{+}{\stackrel{\sim}{\sigma}}$} & Não tenho a menor ideia & $28 \%$ & $55 \%$ & $47 \%$ \\
\hline & Tenho uma vaga noção & $38 \%$ & $28 \%$ & $30 \%$ \\
\hline & Sei, mas preciso estudar mais & $34 \%$ & $17 \%$ & $21 \%$ \\
\hline & Tenho bastante conhecimento & $0 \%$ & $0 \%$ & $2 \%$ \\
\hline \multirow{5}{*}{$\stackrel{\operatorname{Ln}}{\stackrel{2}{\sigma}}$} & Não tenho a menor ideia & $25 \%$ & $42 \%$ & $39 \%$ \\
\hline & Tenho uma vaga noção & $18 \%$ & $20 \%$ & $22 \%$ \\
\hline & Sei, mas preciso estudar mais & $49 \%$ & $28 \%$ & $30 \%$ \\
\hline & Tenho bastante conhecimento & $5 \%$ & $4 \%$ & $4 \%$ \\
\hline & Nulo & $3 \%$ & $6 \%$ & $5 \%$ \\
\hline \multirow{5}{*}{ 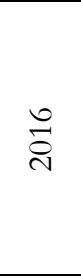 } & Não tenho a menor ideia & $34 \%$ & $63 \%$ & $61 \%$ \\
\hline & Tenho uma vaga noção & $34 \%$ & $25 \%$ & $19 \%$ \\
\hline & Sei, mas preciso estudar mais & $24 \%$ & $10 \%$ & $15 \%$ \\
\hline & Tenho bastante conhecimento & $6 \%$ & $0 \%$ & $0 \%$ \\
\hline & Nulo & $1 \%$ & $1 \%$ & $4 \%$ \\
\hline \multirow{5}{*}{$\stackrel{\curvearrowright}{\stackrel{\sim}{\sigma}}$} & Não tenho a menor ideia & $46 \%$ & $63 \%$ & $59 \%$ \\
\hline & Tenho uma vaga noção & $26 \%$ & $24 \%$ & $28 \%$ \\
\hline & Sei, mas preciso estudar mais & $24 \%$ & $6 \%$ & $11 \%$ \\
\hline & Tenho bastante conhecimento & $3 \%$ & $1 \%$ & $1 \%$ \\
\hline & Nulo & $1 \%$ & $6 \%$ & $1 \%$ \\
\hline
\end{tabular}

Tabela 2 - bloco 2: aplicações do computador Fonte: elaborado pela autora.

Na Tabela 2, no ano de 2014 83\% desconhecem qualquer software para montagem de apresentações e 77\% não conhecem programas para criação de planilhas eletrônicas. No ano de $2015,54 \%$ conhecem editores de textos e $62 \%$ desconhecem qualquer software para montagem de apresentações. Em 2016 80\% não sabe usar nenhum software de planilha eletrônica e 88\% não conhece softwares para montagem de apresentações. Em 2017 87\% dos idosos não conhecem nenhum programa que cria planilhas eletrônicas e a mesma porcentagem de pessoas não conhecem softwares de montagem de apresentações.

A Tabela 3 procurou identificar se os idosos já faziam uso de ferramentas online tais como: navegadores, aceso a internet, redes sociais, pesquisas e até mesmo computação em nuvens. 
Tabela de Frequência Relativa

\begin{tabular}{|c|c|c|c|c|c|c|}
\hline Ano & Alternativas & $\begin{array}{l}7- \\
\text { Navegador }\end{array}$ & $\begin{array}{l}8 \text { - Acesso a } \\
\text { Internet }\end{array}$ & \begin{tabular}{|l|} 
9- Redes \\
Sociais \\
\end{tabular} & $\begin{array}{l}10 \text { - Pesquisa na } \\
\text { Internet }\end{array}$ & $\begin{array}{l}12 \text { - Computação } \\
\text { em Nuvens }\end{array}$ \\
\hline \multirow{5}{*}{$\stackrel{+}{\stackrel{\nu}{\sigma}}$} & $\begin{array}{l}\text { Não tenho a menor } \\
\text { ideia }\end{array}$ & \multirow{2}{*}{$\begin{array}{l}23 \% \\
23 \%\end{array}$} & \multirow{2}{*}{$\begin{array}{l}13 \% \\
4 \%\end{array}$} & \multirow{2}{*}{$\begin{array}{l}21 \% \\
11 \%\end{array}$} & \multirow{2}{*}{$\begin{array}{l}21 \% \\
23 \%\end{array}$} & $68 \%$ \\
\hline & Tenho uma vaga noção & & & & & $19 \%$ \\
\hline & $\begin{array}{l}\text { Sei, mas preciso } \\
\text { estudar mais }\end{array}$ & $49 \%$ & $66 \%$ & $47 \%$ & $43 \%$ & $11 \%$ \\
\hline & $\begin{array}{l}\text { Tenho bastante } \\
\text { conhecimento }\end{array}$ & \multirow{2}{*}{$\begin{array}{l}4 \% \\
2 \%\end{array}$} & $15 \%$ & $19 \%$ & $11 \%$ & $0 \%$ \\
\hline & Nulo & & $2 \%$ & $2 \%$ & $2 \%$ & $2 \%$ \\
\hline \multirow{5}{*}{$\stackrel{n}{\stackrel{n}{i}}$} & $\begin{array}{l}\text { Não tenho a menor } \\
\text { ideia }\end{array}$ & \multirow{3}{*}{$\begin{array}{l}16 \% \\
22 \%\end{array}$} & \multirow{2}{*}{$\begin{array}{l}12 \% \\
10 \%\end{array}$} & \multirow{2}{*}{$\begin{array}{c}20 \% \\
9 \%\end{array}$} & \multirow{2}{*}{$\begin{array}{l}20 \% \\
18 \%\end{array}$} & $46 \%$ \\
\hline & Tenho uma vaga noção & & & & & $19 \%$ \\
\hline & $\begin{array}{l}\text { Sei, mas preciso } \\
\text { estudar mais }\end{array}$ & & $58 \%$ & $52 \%$ & $46 \%$ & $32 \%$ \\
\hline & $\begin{array}{l}\text { Tenho bastante } \\
\text { conhecimento }\end{array}$ & $8 \%$ & $14 \%$ & $14 \%$ & $13 \%$ & $2 \%$ \\
\hline & Nulo & $5 \%$ & $6 \%$ & $5 \%$ & $3 \%$ & $2 \%$ \\
\hline \multirow{5}{*}{$\stackrel{\circ}{\stackrel{1}{2}}$} & $\begin{array}{l}\text { Não tenho a menor } \\
\text { ideia }\end{array}$ & \multirow{2}{*}{$\begin{array}{l}12 \% \\
21 \%\end{array}$} & \multirow{2}{*}{$\begin{array}{l}25 \% \\
31 \%\end{array}$} & \multirow{2}{*}{$\begin{array}{l}18 \% \\
25 \%\end{array}$} & $16 \%$ & $69 \%$ \\
\hline & Tenho uma vaga noção & & & & $18 \%$ & $18 \%$ \\
\hline & $\begin{array}{l}\text { Sei, mas preciso } \\
\text { estudar mais }\end{array}$ & $45 \%$ & $34 \%$ & $45 \%$ & $46 \%$ & $9 \%$ \\
\hline & $\begin{array}{l}\text { Tenho bastante } \\
\text { conhecimento }\end{array}$ & $19 \%$ & $4 \%$ & $6 \%$ & $15 \%$ & $0 \%$ \\
\hline & Nulo & $3 \%$ & $4 \%$ & $6 \%$ & $4 \%$ & $4 \%$ \\
\hline & $\begin{array}{l}\text { Não tenho a menor } \\
\text { ideia }\end{array}$ & $28 \%$ & $20 \%$ & $23 \%$ & $28 \%$ & $66 \%$ \\
\hline & Tenho uma vaga noção & $30 \%$ & $20 \%$ & $20 \%$ & $18 \%$ & $20 \%$ \\
\hline$\stackrel{\sim}{\stackrel{N}{\sigma}}$ & $\begin{array}{l}\text { Sei, mas preciso } \\
\text { estudar mais }\end{array}$ & $35 \%$ & $51 \%$ & $41 \%$ & $40 \%$ & $11 \%$ \\
\hline & $\begin{array}{l}\text { Tenho bastante } \\
\text { conhecimento }\end{array}$ & $3 \%$ & $9 \%$ & $15 \%$ & $14 \%$ & $1 \%$ \\
\hline & Nulo & $5 \%$ & $0 \%$ & $1 \%$ & $1 \%$ & $1 \%$ \\
\hline
\end{tabular}

Tabela 3 - bloco 3: acesso online

Fonte: elaborado pela autora.

Na Tabela 3 no ano de 2014 87\% responderam não saber o que é Computação em Nuvem e 81\% sabiam acessar a internet. Em 2015 73\% sabiam acessar a internet e 66\% tinham bastante conhecimento sobre redes sociais. No ano de 2016 87\% não sabia o que era Computação em Nuvem e 64\% sabia o que era navegador. Em 2017 86\% não sabia o que era Computação em Nuvem e $60 \%$ tinha bastante conhecimento em acessar a internet.

A Tabela 4 visava identificar se eles possuíam algum conhecimento sobre como se proteger e manter suas informações seguras. 
Processo de formação e inclusão tecnológica para a terceira idade

\begin{tabular}{|c|c|c|}
\hline & \multirow{3}{*}{\begin{tabular}{|l|} 
Tabela de Frequência Relativa \\
11 - Segurança da Informação \\
\end{tabular}} \\
\hline & & \\
\hline Ano & Alternativas & \\
\hline \multirow{5}{*}{$\stackrel{\nabla}{\stackrel{\nabla}{\sigma}}$} & Não tenho a menor ideia & $21 \%$ \\
\hline & Tenho uma vaga noção & $21 \%$ \\
\hline & Sei, mas preciso estudar mais & $42 \%$ \\
\hline & Tenho bastante conhecimento & $13 \%$ \\
\hline & Nulo & $4 \%$ \\
\hline \multirow{5}{*}{$\stackrel{\text { 응 }}{\stackrel{\sigma}{\sigma}}$} & Não tenho a menor ideia & $16 \%$ \\
\hline & Tenho uma vaga noção & $12 \%$ \\
\hline & Sei, mas preciso estudar mais & $49 \%$ \\
\hline & Tenho bastante conhecimento & $21 \%$ \\
\hline & Nulo & $3 \%$ \\
\hline \multirow{5}{*}{$\stackrel{0}{\stackrel{0}{\sigma}}$} & Não tenho a menor ideia & $18 \%$ \\
\hline & Tenho uma vaga noção & $19 \%$ \\
\hline & Sei, mas preciso estudar mais & $46 \%$ \\
\hline & Tenho bastante conhecimento & $12 \%$ \\
\hline & Nulo & $4 \%$ \\
\hline \multirow{5}{*}{$\stackrel{\nabla}{\tilde{\sigma}}$} & Não tenho a menor ideia & $19 \%$ \\
\hline & Tenho uma vaga noção & $29 \%$ \\
\hline & Sei, mas preciso estudar mais & $44 \%$ \\
\hline & Tenho bastante conhecimento & $8 \%$ \\
\hline & Nulo & $1 \%$ \\
\hline
\end{tabular}

Na Tabela 4 no ano de 2014 55\% dos idosos afirmaram ter bastante conhecimento de segurança da informação. Em 2015 70\% afirmaram que sabem dos cuidados de segurança na Internet. Em 2016 58\% afirmou que sabem bastante sobre segurança na internet. Em 2017 apenas 51\% afirmou saber dos cuidados de segurança na internet.

Em suma, nota-se que os idosos afirmaram ter bastante conhecimento do computador predominantemente nos anos de 2014 e 2015, porém não sabiam o que era um periférico ou até mesmo um sistema operacional. Nota-se que nos anos 2016 e 2017 a margem diminui e praticamente a metade diz saber usar bem o computador indicando que este tem mais consciência do que se trata as Noções básicas do Computador.

Outro indicador de que os idosos entraram no curso com pouco conhecimento no uso do computador é o fato da maioria destes ao longo dos anos desconhecerem softwares para edições de textos, apresentações e planilhas eletrônicas. Nota-se que estes estão desatualizados quanto ao uso do computador online, sendo que no decorrer dos anos desconhecem o que é computação em nuvem ou até mesmo não sabem usar a internet. 
Processo de formação e inclusão tecnológica para a terceira idade

Outro aspecto importante é a segurança na internet, para evitar perda de dados, vírus, exposição de dados secretos, entre outros, e ao longo dos anos os idosos afirmaram saber que a Internet requer cuidados de segurança. Nos anos de 2014 até 2016 ao término dos cursos não foi aplicada uma avaliação para saber o nível de conhecimento dos idosos.

Em 2017 aplicou-se um questionário de satisfação ao final de cada aula. Os resultados mostram que mais de $80 \%$ dos idosos gostaram da aula de Segurança da Informação e mais de 70\% indicaram como "muito bom" a aula de "Montando Apresentações".

Sabe-se que em 2017 ao ingressarem no curso apenas a metade da sala tinha conhecimento que a internet requer cuidados de segurança e que $87 \%$ da sala não conhecia programas para criar apresentações, quanto a aprendizagem do idoso 65\% em Segurança da Informação e 61\% em Montando Apresentações. Estes são indicadores de que os alunos aprenderam o conteúdo da aula e saíram com noções básicas do uso do computador; outro indicador são os comentários dos idosos (Quadro 3), por meio de uma nuvem de palavras apareceram muitos comentários como: "aula ótima e parabéns".

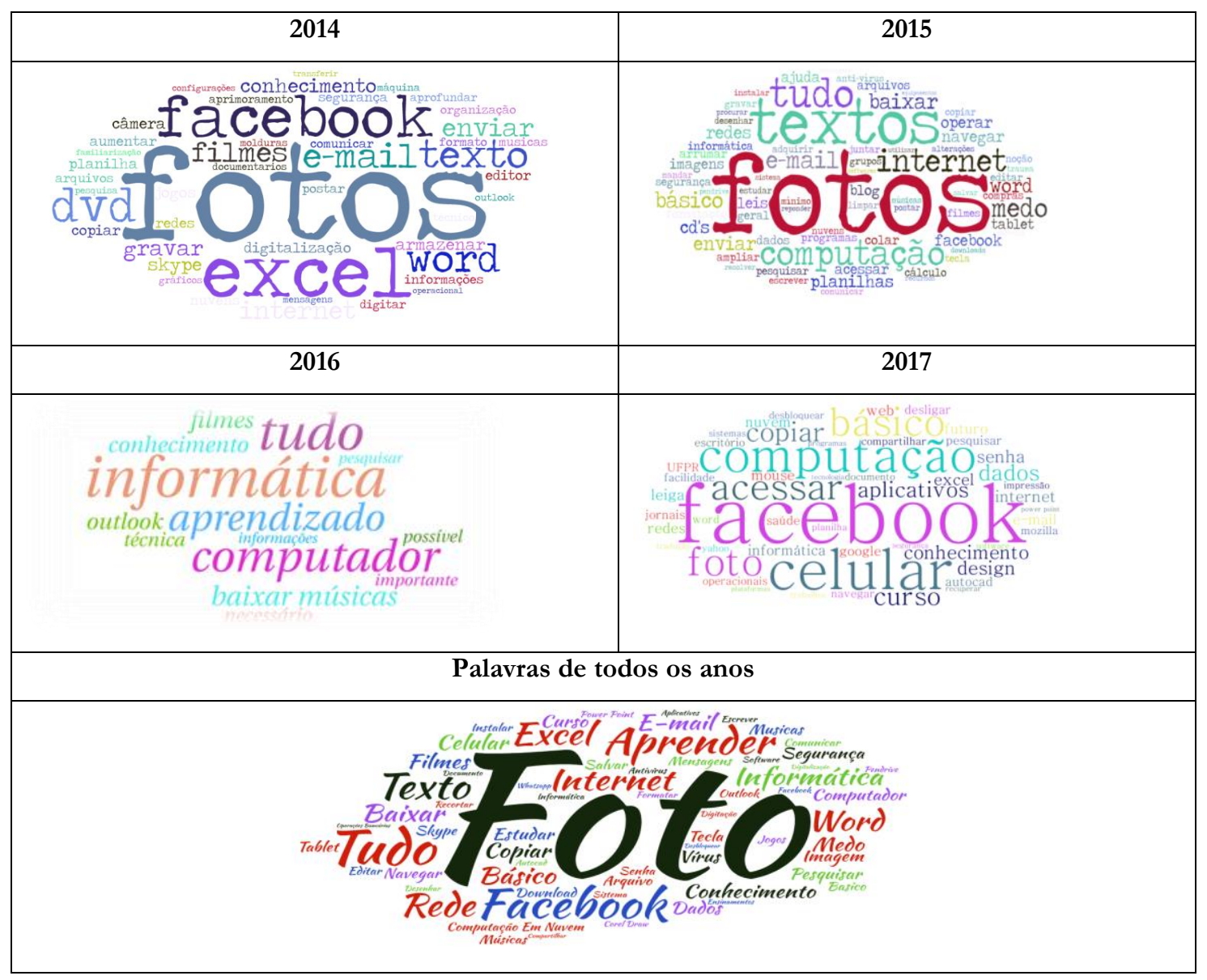

Quadro 2- Nuvens de palavras

Fonte: elaborado pela autora 
Processo de formação e inclusão tecnológica para a terceira idade

Todas as questões dissertativas foram transformadas em nuvens de palavras (Quadro 2) para saber os temas que os idosos mais gostariam de aprender. No ano de 2014 as palavras que mais apareceram foram: "Fotos, Facebook e Excel”. Em 2015 foram: "fotos, textos e tudo". Em 2016 apareceram: "informática, tudo e computador" e no ano de 2017 foram: "Facebook, computação e celular". Juntando as palavras de todos os anos as que ficaram em evidência foram: "foto, tudo e facebook".

Dentre todas as sugestões que mais apareceram ao longo dos anos, a maioria já foram ofertadas nos cursos, exceto edição de fotos e celular, que serão avaliados para ver a possibilidade de ofertar um curso apenas para edição de fotos e smartphones.

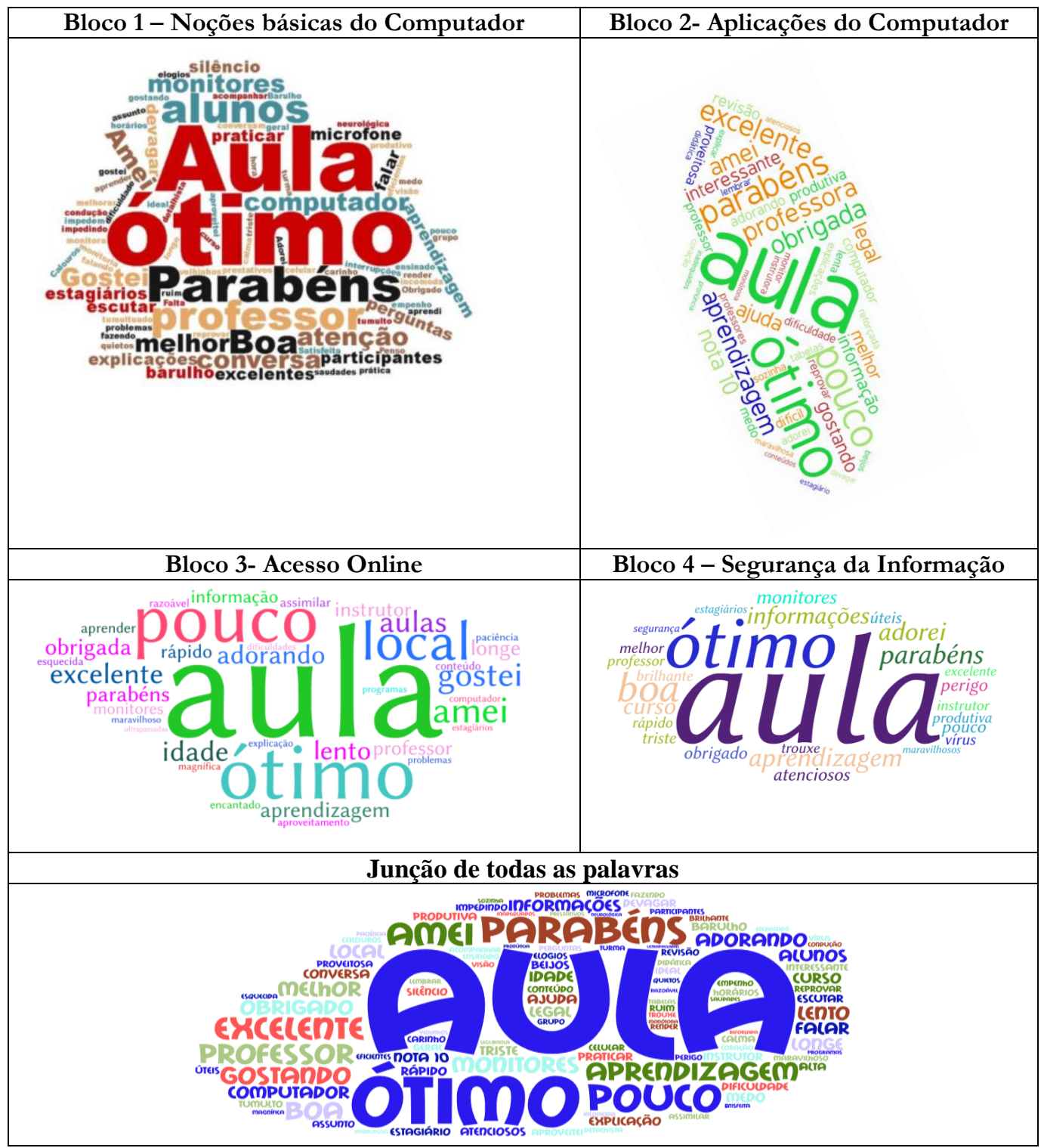

Quadro 3- Nuvens de palavras

Fonte: Elaborado pela autora 
Processo de formação e inclusão tecnológica para a terceira idade

O objetivo do questionário incialmente era saber a aceitação dos cursos e se os idosos estavam aprendendo, porém ocorreram outras melhorias. Ao final de cada aula, os questionários já eram tabulados e os comentários eram enviados aos participantes do curso (professores e monitores).

As melhorias eram comentadas nas aulas seguintes e já corrigidas com ajuda dos participantes tais como: melhoria das aulas, reclamações de barulhos dos idosos e dos monitores, problemas na logística, organização das aulas, melhorias na metodologia, tudo isso contribuiu para um posicionamento mais eficaz dos monitores e professores.

\section{CONSIDERAÇÕES FINAIS}

De modo geral, os objetivos foram atingidos, os idosos apresentaram resultados positivos quanto a aprendizagem adquirida no curso, destacando a importância de executar esse projeto de inclusão digital na UAM.

Além disso, é importante contribuir com pesquisas de e-inclusão na Terceira Idade visto que pouquíssimos grupos em todo o Brasil estão pesquisando sobre esse tema, conforme explanado nesta pesquisa. O projeto de extensão tem possibilitado a inclusão tecnológica e social do idoso.

Durante a formação presencial, o idoso já começa a sua inserção em uma rede social, permitindo que tomem conhecimentos que possibilitam continuar seu processo de educação a distância.

Finalmente, embora não tenha sido objetivo da pesquisa, cabe o relato que dentro do projeto a atividade com idosos tem proporcionado aprendizado em diferentes aspectos: o aluno extensionista, ao ser preparado para desenvolver o material didático e para ser instrutor, vivencia uma realidade que o emociona e o realiza como ser humano, nesta caminhada ele declara melhorar o relacionamento com seus familiares em casa - no caso pais, tios e avós.

\section{REFERÊNCIAS}

BRASIL. Constituição (2003). Lei $n^{\circ}$ 10741, de 01 de outubro de 2003. Dispõe Sobre O Estatuto do Idoso e Dá Outras Providências. Disponível em: <https://goo.gl/xMHlZ $>$. Acesso em: 09 nov. 2016.

IBGE. Projeção da População. Disponível em: < https://goo.gl/U4QQRf>. Acesso em: 02 nov. 2016

SALES, Márcia Barros de. Desenvolvimento de um checklist para a avaliação de 
Processo de formação e inclusão tecnológica para a terceira idade

acessibilidade da web para usuários idosos. 2002. 121 f. Dissertação (Mestrado) - Curso de Engenharia de Produção, Universidade Federal de Santa Catarina, Florianópolis, 2002. Disponível em: $<$ https://repositorio.ufsc.br/bitstream/handle/123456789/83089/185694.pdf?sequence $=1>$.

Acesso em: 02 out. 2016.

SILVA, Ana Paula Alves et al. $\mathbf{O}$ trabalho com alunos com deficiência múltipla: investigação, descoberta e ação pedagógica. Rio de Janeiro: Instituto Municipal Helena Antipoff (iha), 2011. 40 p. $\quad$ Disponível em: $<\underline{\text { https://ihainforma.files.wordpress.com/2011/12/orientac3a7c3b5es-dmu-dezembro-de- }}$ 2011.pdf $>$.Acesso em: 20 nov. 2016.

UAM. Universidade Aberta da Maturidade UFPR . Disponível em: < http://www.uam.ufpr.br/>. Acesso em: 18 nov. 2016.

WORLD HEALTH ORGANIZATION. World report on ageing and health. Luxembourg: World Health Organization, 2015. 260 p. Disponível em: $<$ http://apps.who.int/iris/bitstream/10665/186463/1/9789240694811 eng.pdf>. Acesso em: 18 nov. 2016. 